$$
\begin{aligned}
& \text { بررسى دوشكلى جنسى در نسبت طول انگشتان دوم تا جهمارم (2D:4D) در دو كونه وزغ } \\
& \text { سبز و وزغ نابيلجهاى }
\end{aligned}
$$

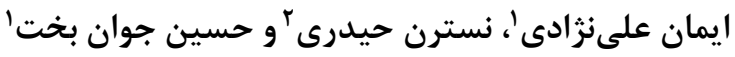

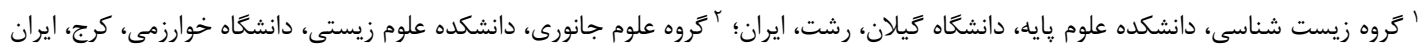

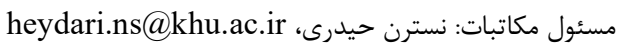

קكيده. دوشكلى جنسى در نسبت طول انگشتان يك ويزّى مورفولوزيكى حاصل از برهمكنش بين هورمونهاى جنسى و زنهاى Hox قبل از تولد بوده كه

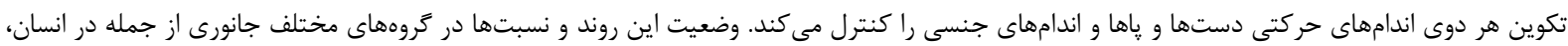

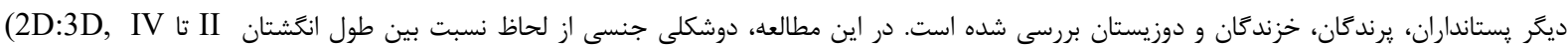

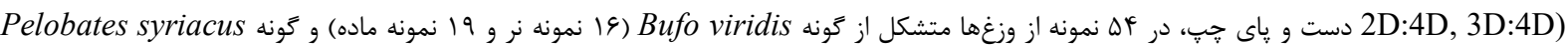

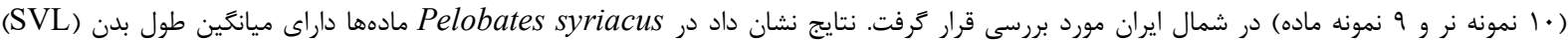

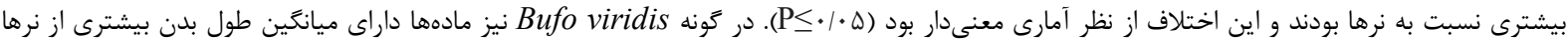

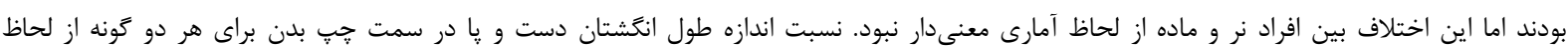
(2D:3D, 2D:4D, 3D:4D)

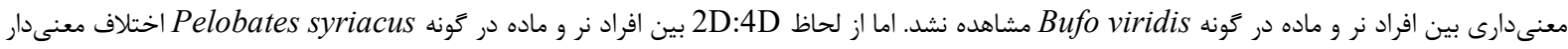

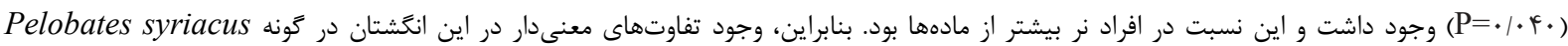

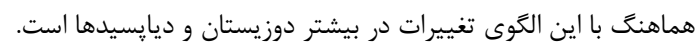
كلمات كليدى. تكوين، دوزيستان، زن هاكس، مهره داران، مورفولوزى

\title{
Sexual dimorphism in digit length ratios of the second to fourth digits (2D:4D) in two species of green toads (Pelobates syriacus Boettger, 1889 and Bufo viridis (Laurenti, 1768))
}

\author{
Iman Alinezhadi ${ }^{1}$, Nastaran Heidari ${ }^{2}$ \& Hossein Javanbakht ${ }^{1}$ \\ ${ }^{1}$ Department of Biology, Faculty of Science, University of Guilan, Rasht, Iran; ${ }^{2}$ Department of Animal Biology, Faculty \\ of Biological Sciences, Kharazmi University, Karaj, Iran \\ Corresponding author: Nastaran Heidari, heydari.ns@khu.ac.ir
}

\begin{abstract}
Sexual dimorphism in the ratio of digits length is a morphological feature resulted from the interaction between sex hormones and prenatal Hox genes, the latter is known to control the development of both limbs and genitals. The status of this trend and ratios have been investigated in various animal groups, including humans, other mammals, birds, reptiles, and amphibians. In this study, the body length and sexual dimorphism in the second-to-fourth, second-to-third and third-to-fourth digit lengths ratios (i.e., 2D:3D, 2D:4D, 3D:4D) of left fore and hind limbs were investigated in 54 specimens of toads collected from the northern Iran, including Bufo viridis (16 males and 19 females) and Pelobates syriacus (10 males and 9 females). In addition, the body length of the studied specimens were recorded. The results showed that the average body length (SVL) of female individuals of Pelobates syriacus was higher than those in males, which was found to be statistically significant $(\mathrm{P} \leq 0.05)$. Meanwhile, the average body length (SVL) of female individuals of Bufo viridis was found to be higher than those in males, however, the difference was not statistically significant. No sexual dimorphism was detected in the second-to-fourth, second-to-third and third-to-fourth digit lengths ratios of left fore and hind limbs between the male and female undividuals of Bufo viridis. However, the second-to-fourth digit ratio
\end{abstract}


(2D:4D) in Pelobates syriacus species were found to be significantly different $(\mathrm{P}=0.040)$ between the male and female individuals, as the ratio was higher in males than females. Therefore, it could be concluded that the sexual dimorphism in 2D:4D of Pelobates syriacus species is consistent with those in most amphibians and diapsids.

Key words. Amphibia, development, Hox gene, morphology, vertebrates

جنينى بيان مىشوند (Kondo et al., 1997). بنابراين تكوين

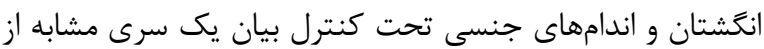

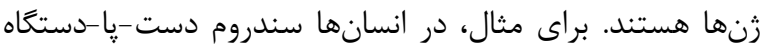

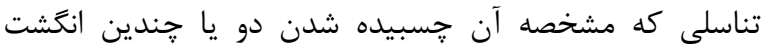

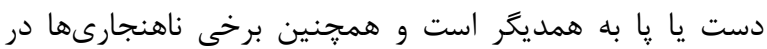

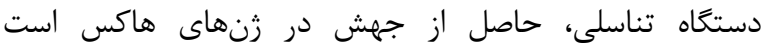
Mortlock \& Innis, 1997) Manning et al., ) رابطه بين تكوين اندامهاى حركتى و كَّنادها

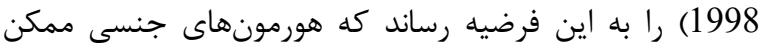
است به صورت علت و معلولى مرتبط با متغيرهاى درون و بين جنسى در نسبت انگشتان باشد كه ممكن است در نتيجه برهم كنش بين بيان زنهاى هاكس و توليد استروئيدهاى جنسى

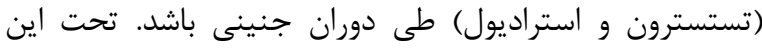

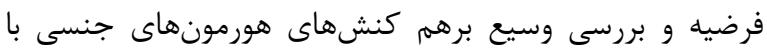

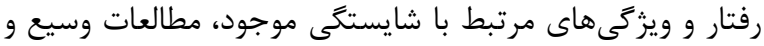

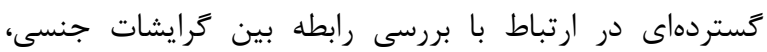

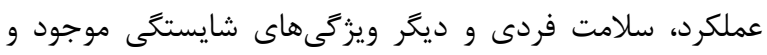

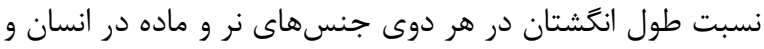

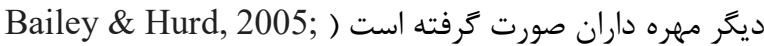
Fink et al., 2005; Flegr et al., 2005; Kempel et al., 2005; Romano et al., 2006; Manning, 2002; Putz et وائ

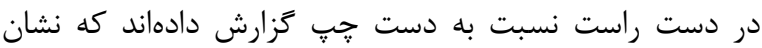
دهنده يك تقارن جهت دار در حساسيت اندامهاى حركتى به هورمونهاى جنسى بوده كه مصداق بارز آن نسبت دإيت دايينتر

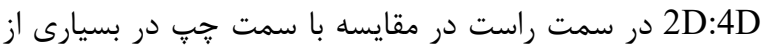

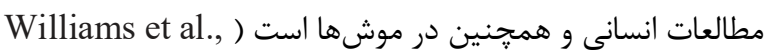
2000; Brown et al., 2002a, b تكاملى در رده مهره داران بشدت محافظت شده است (Krumlauf, 1994). دوشكلى جنسى در درد نسبت بين انخشتان 2D:4D در تقريبا تمامى كروههاى مهره دارن جهاريا از جمله دئه

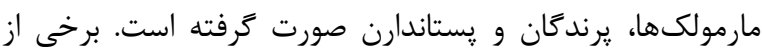
اين موارد شامل فنج راه راه كونه (Taenopygia guttata) كه

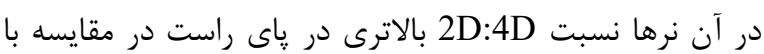

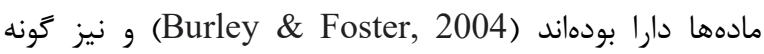
Phasianus colchicus
مقلهمه دوشكلى جنسى در نسبت طول انگشتان دستها و پاها بويزه در نسبت طول انَشتان دوم به جههارم دستها در انسان ها بسيار مورد توجه و بررسى قرار كرفته است كه در آن افراد نر داراى داد

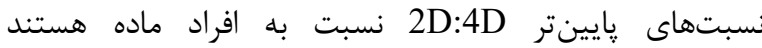
(Manning, 2002; Peters et al., 2002) دوشكلىهاى جنسى در ابتداى مراحل جنينى شكل كرفته و تا مراحل انتهايى رشد، در موجودات تثبيت مىشود ( McIntyre et al., 2005; Trivers et al., 2006 نسبت طول انگشتان همجنين در ديخر جفت انگشتان اندامهاى

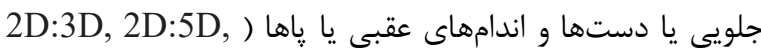

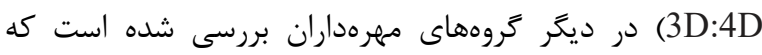

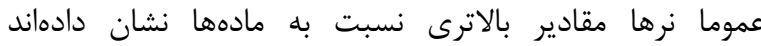
(McFadden \& Shubel, 2002; Manning et al., 2003) بعلاوه، تقارن جهت دار در نسبت 2D:4D در بسيارى از مطالعات

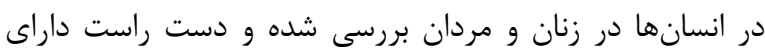

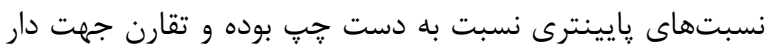

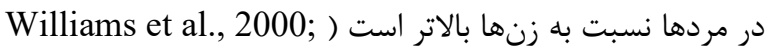
(Manning, 2002

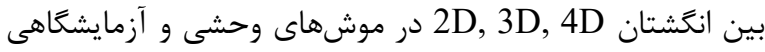
Brown et al., 2002a; Manning et al., 2003; بودند Leoni et al., 2005; Bailey et al., 2005 الكوهاى متغير تفاوتهاى جنسى در انخشتان (2D:4D) در دادئ

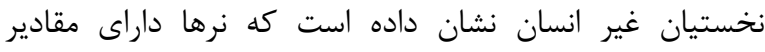

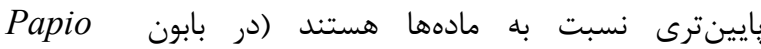
(hamadryas )، اما در بابونهاى گينهاى (Papio papio)، كوريل ها (Gorilla gorilla) و شاميانزهها (Pan troglodytes) McFadden \& Bracht, ) نرها داراى نسبت بالاترى هستند 2003, 2005; Roney et al., 2004

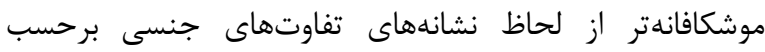

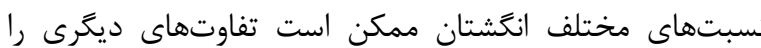

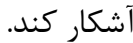
تكوين اندامهاى حركتى در مهره داران تحت كنترل يك سرى دان

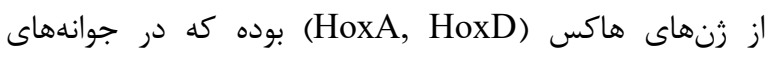
جنسى جنينى (پيش ساخت اندامهاى جنسى) در طى تكوين 
بخش كياشهر شهرستان آستانه اشرفيه و نمونههاى وزغ 4إبيلجهاى در محدوده روستاى كالش كلام ( (433536E; 39S از توابع شهرستان لنكرود جمع آورى ترديد.

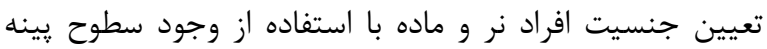

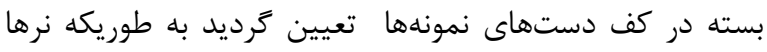

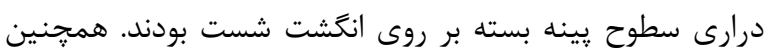

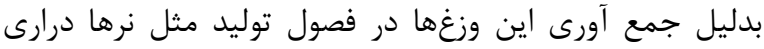

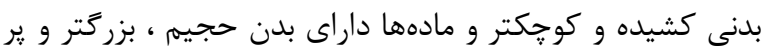

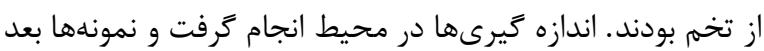

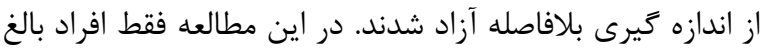

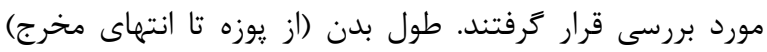

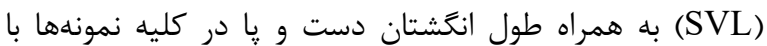
استفاده دستخاه كوليس ديجيتال با دقت / / • ميلىمتر اندازه

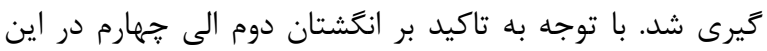

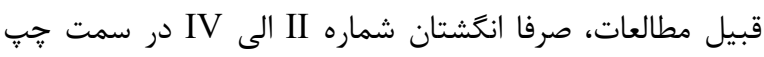

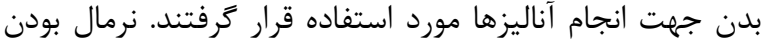

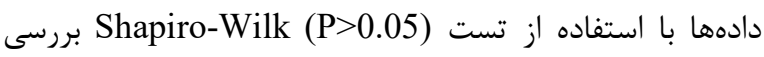

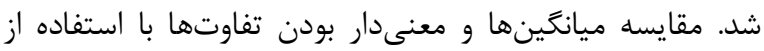

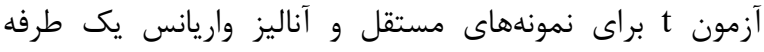

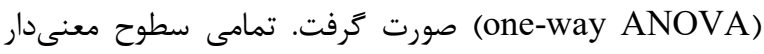
در سطح ه • • در نظر گرفته شدند. به منظور بررسى و تعيين اثر

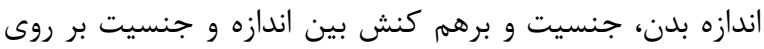
اندازه نسبت طول انگشتان متغيره به كمك نرم افزار 21 SPSS استفاده شد.

\section{نتايج} نتيجه آزمون Shapiro-Wilk نشان داد كه براى صفات مورد

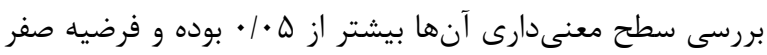

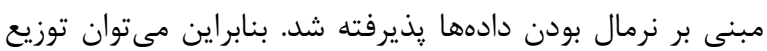

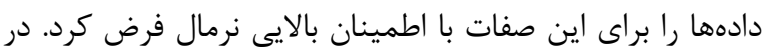

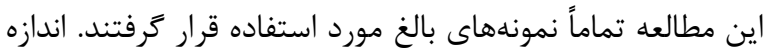

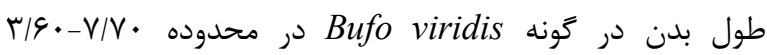
Pelobates syriacus در محدوده

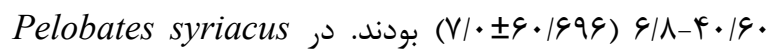
مادها داراى ميانكين طول بدن (SVL) بيشترى نسبت به نرها

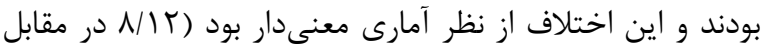
Bufo viridis نيز مادهها داراى

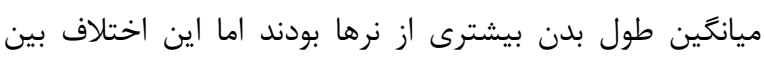
افراد نر و ماده از لحاظ آمارى معنى دار نبود (شكل كآن).
كدام از نسبتهاى انگشتان در هر دو را مشاهده نشده است

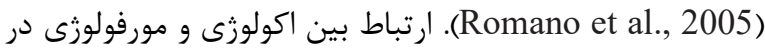
بسيارى از تاكسونهاى جانورى مورد بررسى قرار كرفته است. ارتباط بين طول نسبى انگشتان و ويزگى هاى زيستخاهى كونه

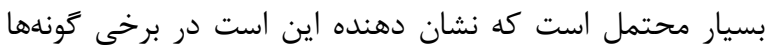

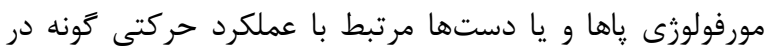

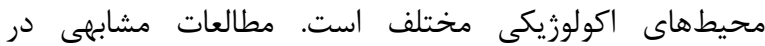

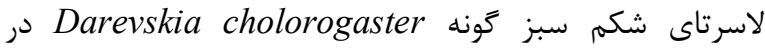
شمال ايران توسط (2019) Noghanchi \& Javanbakht صورت كرفته كه اظهار داشتند اين نسبتها در كونه مورد

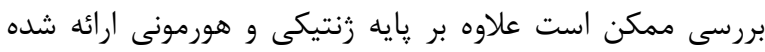

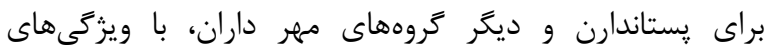

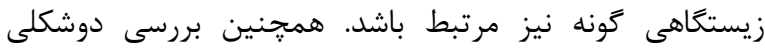

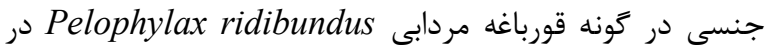
شمال ايران توسط Rajabi \& Javanbakht (2019) نشان از وجود تفاوتهاى معنىدار در اندازه انگشتان اول و و سوم (1D:3D)

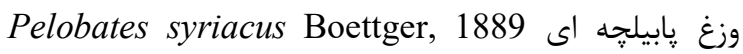
كَونه اى از وزغهاى خانواده Pelobatida است كه از قسمتهاى

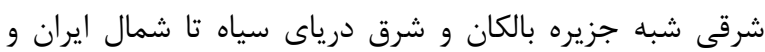

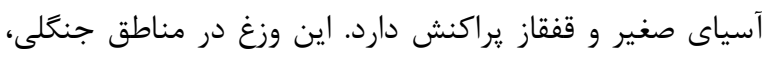

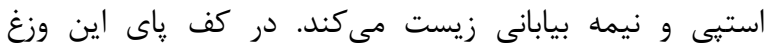
توبركول يشتى توسعه يافته و شبيه بيلجه شده است كه وجه

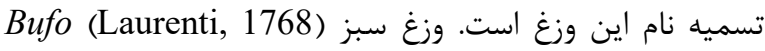
viridis استٍ و كوهستانى، بيابانى، جنكلى و حاشيه شهرها با يراكنش إنش

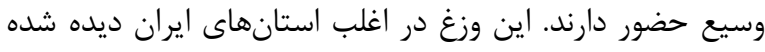

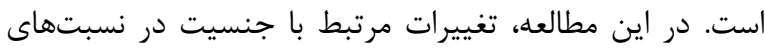

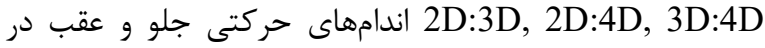

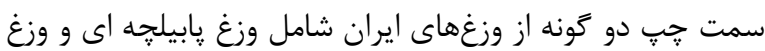

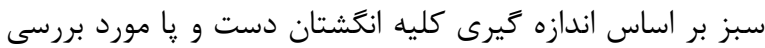
قرار كرفته است.

\section{مواد و روشها}

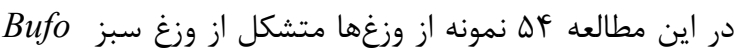
إن viridis Pelobates syriacus

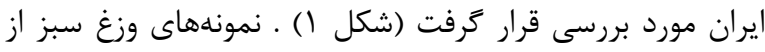

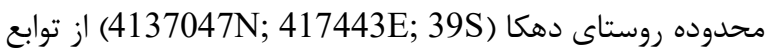



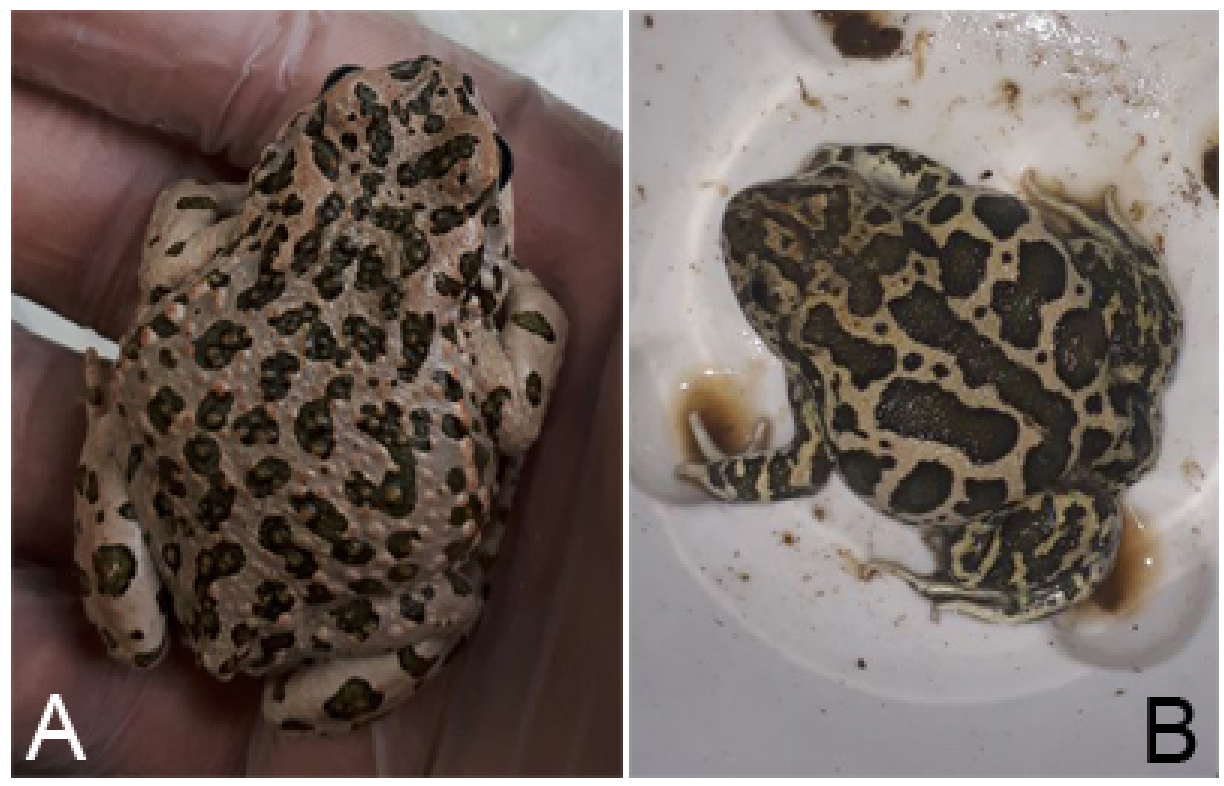

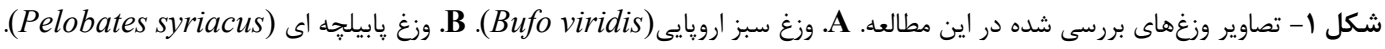

Fig. 1. Photographs of toads investigated in this study. A. European green toad (Bufo viridis). B. Eastern spadefoot toad (Pelobates syriacus).

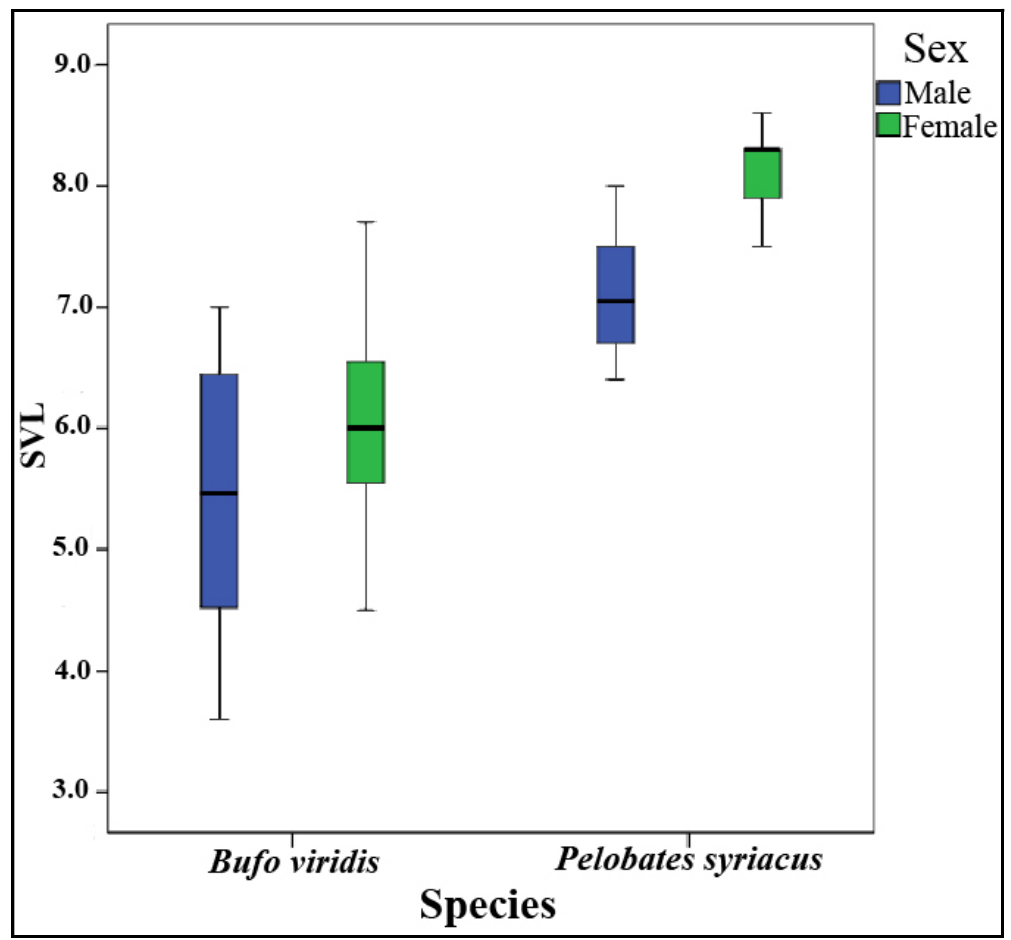

شكل r - نمودار باكس يلات افراد نر و ماده دو گونه مورد بررسى از لحاظ ويزگى اندازه بدن.

Fig. 2. Box plot graph of male and female specimens in two examined species based on snout-vent length (SVL). 


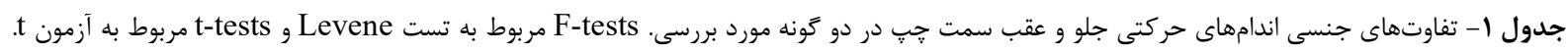

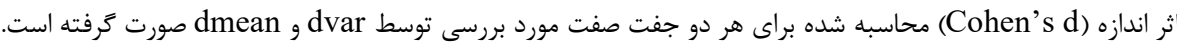

Table 1. Summary of sex-related differences in left fore and hind limb in two examined species. F-tests refer to the Levene's test for the equality of variances, whereas the t-tests refer to sex differences. Effect sizes (Cohen's d) are calculated for each of these two tests (dvar and dmean, respectively).

\begin{tabular}{|c|c|c|c|c|c|c|c|c|}
\hline \multirow{9}{*}{$\begin{array}{l}\text { Bufo } \\
\text { viridis }\end{array}$} & Measure & Males $(\mathrm{N}=16)$ & Females $(\mathrm{N}=19)$ & $\mathbf{F}$ & $d_{\text {var }}$ & $\mathbf{t}$ & p & $\mathrm{d}_{\text {mean }}$ \\
\hline & \multicolumn{8}{|l|}{ Forelimb } \\
\hline & 2D:3D & 0.8200 & 0.7879 & 0.804 & 1 & -1.418 & 0.376 & 1 \\
\hline & 2D:4D & 1.1538 & 1.1203 & 0.237 & 1 & -3.142 & 0.630 & 1 \\
\hline & 3D:4D & 1.4081 & 1.4223 & 0.059 & 1 & -1.112 & 0.809 & 1 \\
\hline & \multicolumn{8}{|l|}{ Hind limb } \\
\hline & 2D:3D & 0.6603 & 0.6106 & 1.983 & 1 & -0.714 & 0.168 & 1 \\
\hline & 2D:4D & 0.4055 & 0.3680 & 2.909 & 1 & 0.417 & 0.097 & 1 \\
\hline & 3D:4D & 0.6241 & 0.6147 & 0.060 & 1 & 1.854 & 0.814 & 1 \\
\hline \multirow{9}{*}{$\begin{array}{c}\text { Pelobates } \\
\text { syriacus }\end{array}$} & Measure & Males $(\mathrm{N}=10)$ & Females $(N=9)$ & $\mathbf{F}$ & $\mathbf{d}_{\mathrm{var}}$ & $\mathbf{t}$ & $\mathbf{p}$ & $\mathbf{d}_{\text {mean }}$ \\
\hline & \multicolumn{8}{|l|}{ Forelimb } \\
\hline & 2D:3D & 0.7404 & 0.7147 & 0.444 & 1 & -1.214 & 0.514 & 1 \\
\hline & 2D:4D & 1.0659 & 0.9940 & 2.879 & 1 & -2.941 & 0.108 & 1 \\
\hline & 3D:4D & 1.4701 & 1.3904 & 0.675 & 1 & -1.004 & 0.423 & 1 \\
\hline & \multicolumn{8}{|l|}{ Hind $\operatorname{limb}$} \\
\hline & 2D:3D & 0.6429 & 0.7149 & 1.721 & 1 & -1.714 & 0.207 & 1 \\
\hline & 2D:4D & 0.5033 & 0.4481 & 4.932 & 1 & 0.821 & 0.040 & 1 \\
\hline & 3D:4D & 0.6956 & 0.7187 & 0.603 & 1 & 1.252 & 0.448 & 1 \\
\hline
\end{tabular}

جنسى انگشتان در يك گونه دوزيست اگر وجود داشته باشد و طبق الكوى بدست آمده در ديإِيدها اخر نسبت 2D:4D در نرها بيشتر

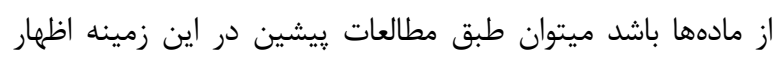
كرد كه دوشكلى جنسى در اين صفت ممكن است حالت اجدادى در گونه مورد بررسى باشد. طبق فرضيههاى ارائه شده در اين خصوص، نسبت طورل نول

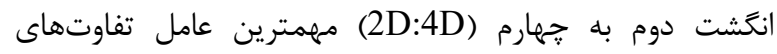
مورفولوزيكى اين صفت در گروههاى مختلف جانورى بوده كه در

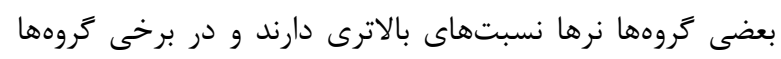
مادها نسبت بالاترى دارند. دوشكلى جنسى انگشتان همجنين

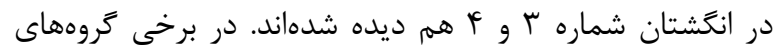
جانورى انگشتان دست اين ويزگى دو شكلى جنسى را بهتر نشان

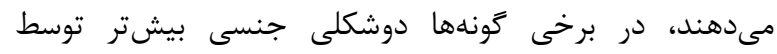

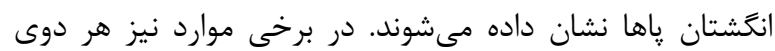

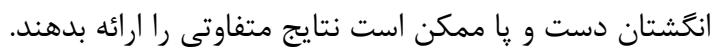

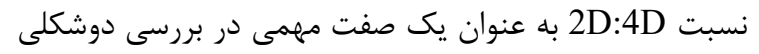
جنسى مهره داران مىتواند مورد استفاده قرار گيرد. اين قبيل از

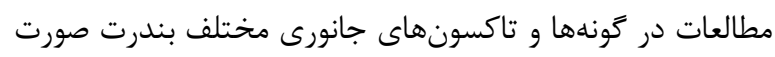
گرفته است و مطالعه حاضر مىتواند شواهد كاملتر و بهترى از
نسبت اندازه طول انخشتان دست و یا در سمت جي بدن براى

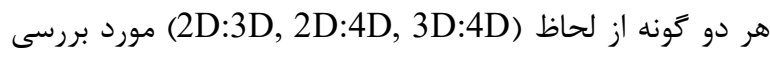
قرار گرفت. نتايج نشان داد كه در هيج كدام از صفات مورد بررسى در اندامهاى حركتى جلويى و عقبى اختلاف معنى دارى بين افراد نر و ماده در كونه Bufo viridis مشاهده نشد. اما از از

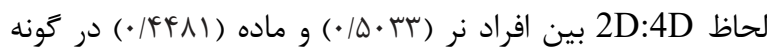
Pelobates syriacus دوم و קههارم اندامهاى عقبى وجود داشت (شكل س). جزئيات بيشتر اين مقادير در جدول الرمائه شده است وجدود دانت

در اين مطالعه دوشكلى جنسى در نسبت طول انگشتان دست و پا

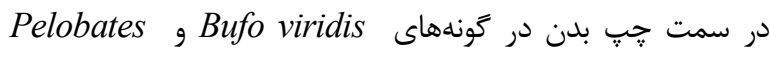
syriacus

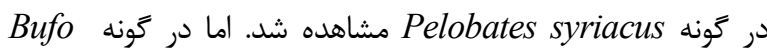

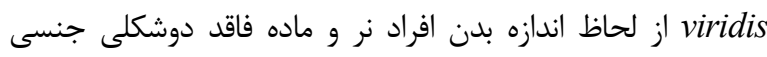

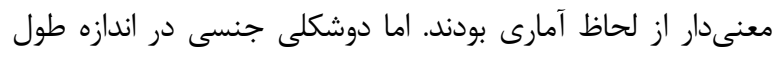

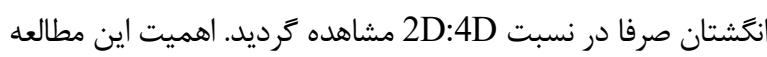
در اين است كه طبق مطالعات Chang (2006) الخوى دوشكلى كرديت 
تعداد انخشتان در اندامهاى جلويى در دوزيستان ميتواند مسئول

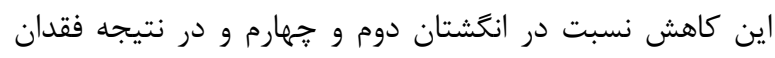
دوشكلى جنسى در اين اندام باشد (Chang, 2008). در ميان ديخر دوزيستان بررسى شده در ايران، تغييرات درون

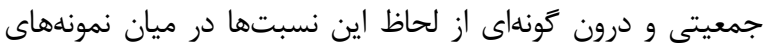
بررسى شده مشاهده شده است (Rajabi \& Javanbakht, 2019). اما، الكوى دوشكلى جنسى در نسبت طول انخَتان در دو گَونه مورد بررسى در اين مطالعه مشابه بود. بنابراين پيش بيشى بينى و تعميم الكَى

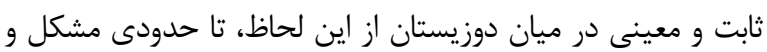

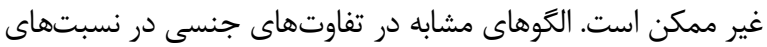
مشاهده شده طول انگشتان در دو گونه مورد بررسى نشان دهنده

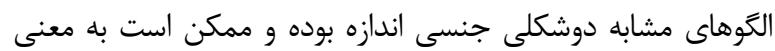
وجود يك مكانيسم اساسى مشترك شكل دهنده دوشكلى جنسى در هر دوى ويثزگىهاى بدنى و نسبتهاى انگشتان در اين گَونهها

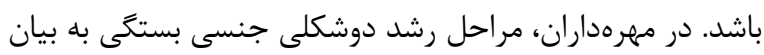

وضعيت دوشكلى جنسى در دوزيستان ارائه بدهد و اطلاعات 2D:4D موجود در اين زمينه را بهبود بخشد. نسبتهاى بالاى در گونه Pelobates syriacus در افراد نر نسبت به افراد ماده، موافق و هماهنَ با بيشتر گونهاى مهره داران از جمله فنج راه راه (Burley \& Foster, 2004)، مرغ بهشتى ( Saino et al., ) 2007)، مارمولكهاى جنس Rubolini et al., ) Podarcis 2006) و (Chang et al., 2006) Anolis) است. فقدان كامل دوشكلى جنسى در نسبت 2D:4D در اندامهاى جلويى و عقبى كونه Bufo viridis مى تواند به دليل يايين بودن دامنه تغييرات

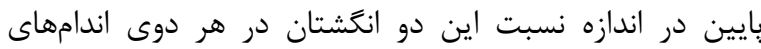
جلويى و عقبى گونه Bufo viridis و در اندامهاى جلويى گونه Pelobates syriacus تكوينى كه مسئول اين اختلافات و عدم وجود تفاوتهاى جنسى در اين نسبتها به خصوص در اندامهاى جلويى باشد كاملا مشخص نيست، اما اين امكان وجود دارد كه مكانيسم كاهش به

جدول r- اثر اندازه، طول بدن، جنسيت و برهم كنش آنها بر روى نسبت طول انگشتان 3D: 4D 2D: 3D, 2D: 4D اندامهاى جلويى و عقبى (سمت

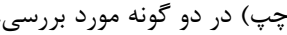

Table 2. The effect of sex, snout-vent length (SVL), and their interaction on the digit ratios 2D: 4D, 3D: 4D and 2D: $3 \mathrm{D}$ of the left fore and hind limb in two examined species.

\begin{tabular}{|c|c|c|c|c|c|c|c|c|c|c|}
\hline & \multicolumn{4}{|c|}{ 2D:3D } & \multicolumn{3}{|c|}{ 2D:4D } & \multicolumn{3}{|c|}{ 3D:4D } \\
\hline \multirow{11}{*}{ Bufo viridis } & Forelimb & df & F-ratio & $\mathbf{P}$ & df & F-ratio & $\mathbf{P}$ & df & F-ratio & $\mathbf{P}$ \\
\hline & \multicolumn{10}{|c|}{ Factor } \\
\hline & Sex & 1 & 1.906 & 0.261 & 1 & 8.731 & 0.060 & 1 & 0.018 & 0.903 \\
\hline & SVL & 1 & 0.993 & 0.594 & 1 & 8.792 & 0.049 & 1 & 2.061 & 0.304 \\
\hline & SVL by Sex & 1 & 2.973 & 0.199 & 1 & 29.399 & 0.009 & 1 & 2.292 & 0.263 \\
\hline & & \multicolumn{3}{|c|}{ 2D:3D } & \multicolumn{3}{|c|}{ 2D:4D } & \multicolumn{3}{|c|}{ 3D:4D } \\
\hline & Hind limb & df & F-ratio & $\mathbf{P}$ & df & F-ratio & $\mathbf{P}$ & df & F-ratio & $\mathbf{P}$ \\
\hline & \multicolumn{10}{|c|}{ Factor } \\
\hline & Sex & 1 & 21.095 & 0.019 & 1 & 8.869 & 0.059 & 1 & 1.448 & 0.315 \\
\hline & SVL & 1 & 15.574 & 0.022 & 1 & 1.382 & 0.453 & 1 & 2.143 & 0.292 \\
\hline & SVL by Sex & 1 & 4.345 & 0.128 & 1 & 1.670 & 0.357 & 1 & 1.932 & 0.312 \\
\hline \multirow{12}{*}{$\begin{array}{c}\text { Pelobates } \\
\text { syriacus }\end{array}$} & \multicolumn{4}{|c|}{ 2D:3D } & \multicolumn{3}{|c|}{ 2D:4D } & \multicolumn{3}{|c|}{ 3D:4D } \\
\hline & Forelimb & df & F-ratio & $\mathbf{P}$ & df & F-ratio & $\mathbf{P}$ & df & F-ratio & $\mathbf{P}$ \\
\hline & \multicolumn{10}{|c|}{ Factor } \\
\hline & Sex & 1 & 2.108 & 0.345 & 1 & 7.234 & 0.120 & 1 & 0.124 & 0.871 \\
\hline & SVL & 1 & 1.125 & 0.852 & 1 & 9.482 & 0.088 & 1 & 3.101 & 0.524 \\
\hline & SVL by Sex & 1 & 2.802 & 0.288 & 1 & 27.988 & 0.007 & 1 & 1.857 & 0.547 \\
\hline & & \multicolumn{3}{|c|}{ 2D:3D } & \multicolumn{3}{|c|}{ 2D:4D } & \multicolumn{3}{|c|}{ 3D:4D } \\
\hline & Hind limb & df & F-ratio & $\mathbf{P}$ & df & F-ratio & $\mathbf{P}$ & df & F-ratio & $\mathbf{P}$ \\
\hline & \multicolumn{10}{|c|}{ Factor } \\
\hline & Sex & 1 & 24.194 & 0.411 & 1 & 8.701 & 0.157 & 1 & 2.221 & 0.452 \\
\hline & SVL & 1 & 14.571 & 0.014 & 1 & 2.014 & 0.252 & 1 & 3.412 & 0.752 \\
\hline & SVL by Sex & 1 & 5.741 & 0.412 & 1 & 2.410 & 0.427 & 1 & 2.254 & 0.489 \\
\hline
\end{tabular}




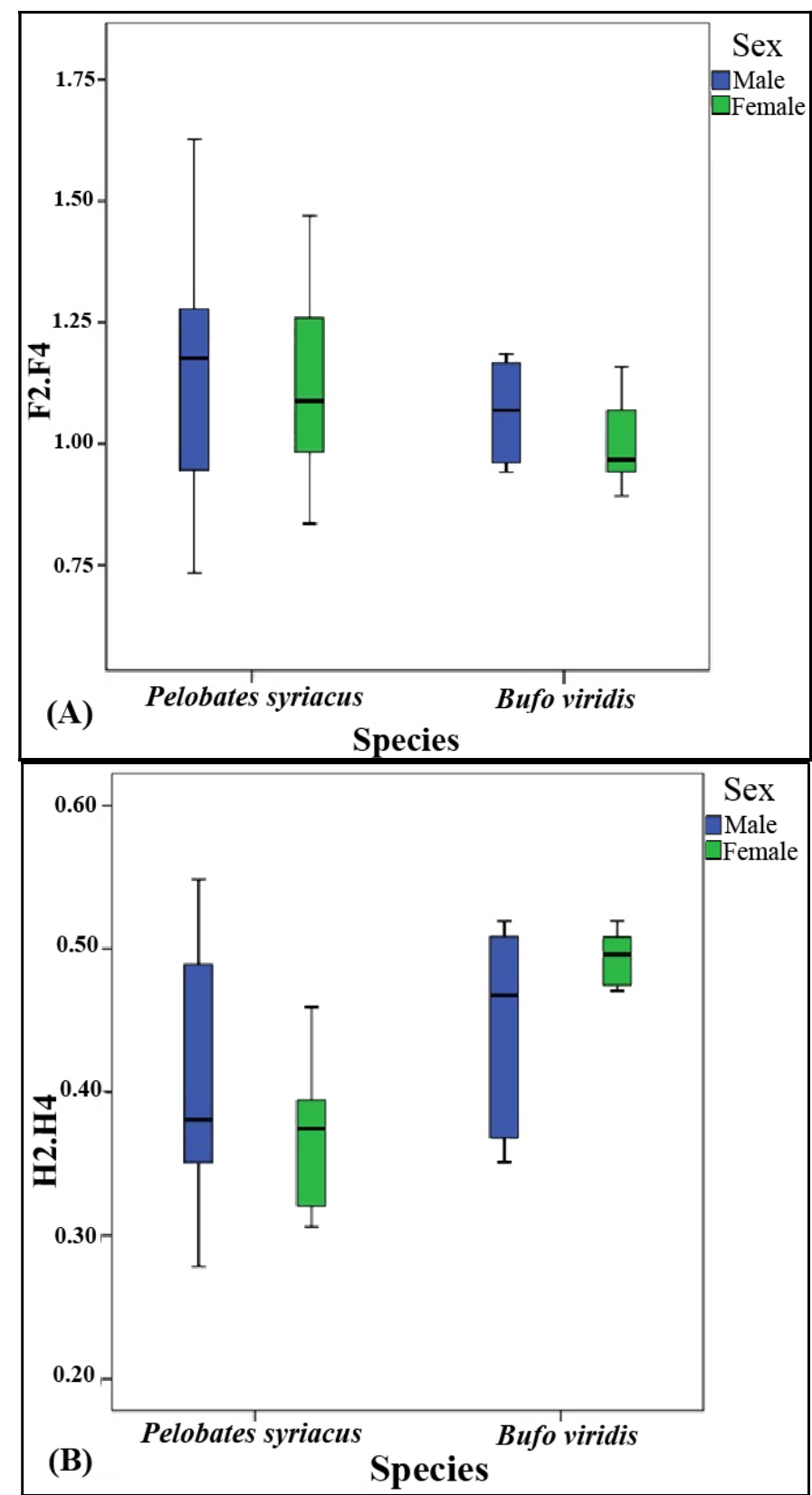

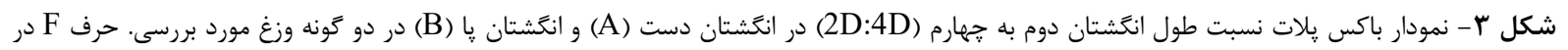

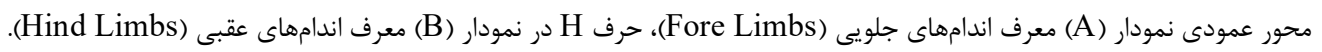

Fig. 3. Box plot diagram of the ratios of the length of the second to fourth digits (2D: 4D) in the fingers (A) and toes (B) in two examined species of toads. The letter $\mathrm{F}$ in the vertical axis of the diagram represents the fingers of the front limbs (Fore Limbs), the letter $\mathrm{H}$ represents the hind limbs (Hind Limbs).

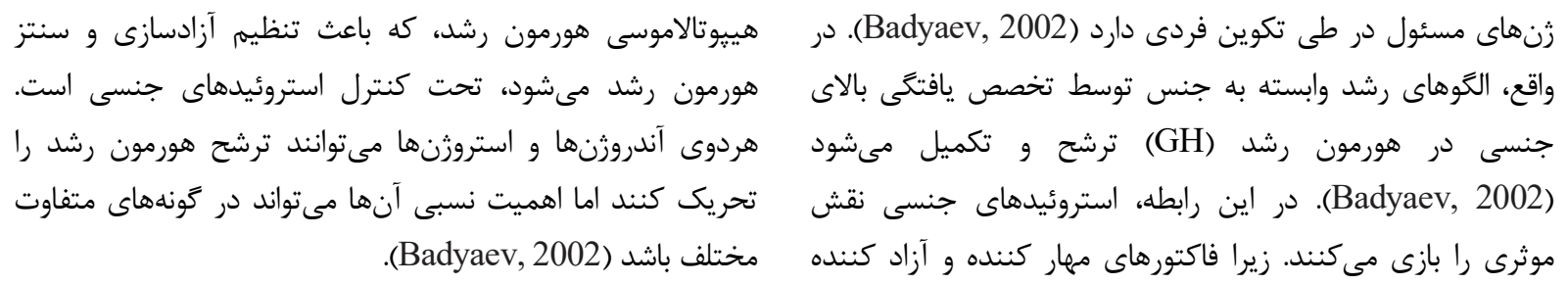




\section{REFERENCES}

Badyaev, A. 2002. Growing apart: an ontogenetic perspective on the evolution of sexual size dimorphism. Trends in Ecology \& Evolution 17: 369-378.

Bailey, A. \& Hurd, L. 2005. Finger length ratio (2D:4D) correlates with physical aggression in men but not in women. Biological Psychology 68: 215-222.

Bailey, A., Wahlsten, D. \& Hurd, P. 2005. Digit ratio (2D:4D) and behavioral differences between inbred mouse strains. Genes Brain and Behavior 4: 318-323.

Brown, W.M., Finn, C.J. \& Breedlove, S. 2002a. Sexual dimorphism in digit-length ratios of laboratory mice. The Anatomical Record 267: 231-234.

Brown, W.M., Finn, C.J., Cooke, B.M. \& Breedlove, S.M. 2002b. Differences in finger length ratios between self-identified "butch" and "femme". Archives of Sexual Behavior 31: 123-127.

Burley, N. \& Foster, V. 2004. Digit ratio varies with sex, egg order and strength of mate preference in zebra finches. Proceedings of the Royal Society B: Biological Sciences 271: 239-244.

Chang, J.L. 2008. Sexual dimorphism of the second-tofourth digit length ratio (2D:4D) in the strawberry poison dart frog (Oophaga pumilio) in Costa Rica. Journal of Herpetology 42: 414-416.

Chang, J., Doughty, J. Wade, L. \& Lovern, M. 2006. Sexual dimorphism in the second-to-fourth digit length ratio in Green Anoles, Anolis carolinensis (Squamata: Polychrotidae) from the southeastern United States. Canadian Journal of Zoology 84: 1489-1494.

Fink, B., Grammer, K., Mitteroecker, P., Gunz, P., Schaefer, K., Bookstein, F. \& Manning, J. 2005. Second to fourth digit ratio and face shape. Proceedings of the Royal Society B: Biological Sciences 272: 1995-2001.

Flegr, J., Hruskova, M., Hodny, Z., Novotna, M., \& Hanusova, J. 2005. Body height, body mass index, waist-hip ratio, fluctuating asymmetry and second to fourth digit ratio in subjects with latent toxoplasmosis. Parasitology 130: 621-628.

Kempel, P., Gohlke, B., Klempau, J., Zinsberger, P., Reuter, M. \& Hennig, J. 2005. Second-to-fourth digit length, testosterone and spatial ability. Intelligence 33: 215-230.

Kondo, T., Zakany, J., Innis, J. \& Duboule, D. 1997. Of fingers, toes and penises. Nature 390: 29.

Krumlauf, R. 1994. Hox genes in vertebrate development. Cell 78: 191-201.

Leoni, B., Canova, L. \& Saino, N. 2005. Sexual dimorphism in metapodial and phalanges length ratios in the wood mouse. The Anatomical Record Part A Discoveries in Molecular Cellular and Evolutionary Biology 286A: 955-961.

McFadden, D. \& Shubel, E. 2002. Relative lengths of finger and toes in human males and females. Hormones and Behavior 42: 492-500.

McFadden, D. \& Bracht, M. 2003. The relative lengths and weights of metacarpals and metatarsals in baboons (Papio hamadryas). Hormones and Behavior 43: 347-355.

$$
\begin{aligned}
& \text { در نهايت به طور خلاصه، نسبت 2D:4D در گونه Pelobates } \\
& \text { syriacus }
\end{aligned}
$$

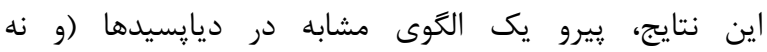

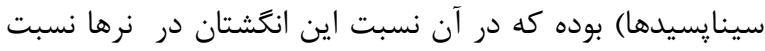

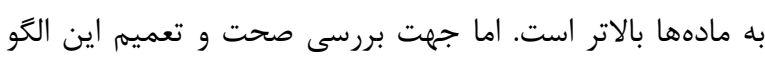

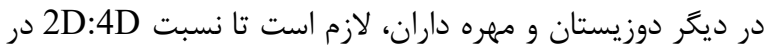

$$
\begin{aligned}
& \text { تعداد گونههاى بيشترى از مهره داران مورد بررسى قرار گيرد. } \\
& \text { سياسگزارى } \\
& \text { نويسندگان مقاله از مسئولين موزه و آزمايشگاه گروه زيست }
\end{aligned}
$$

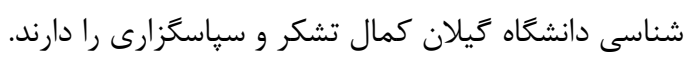


McFadden, D. \& Bracht, M. 2005. Sex differences in the relative lengths of metacarpals and metatarsals in gorillas and chimpanzees. Hormones and Behavior 47: 99-111.

McIntyre, M., Ellison, P., Lieberman, D., Demerath, E. \& Towne, B. 2005. The development of sex differences in digital formula from infancy in the Fels longitudinal study. Proceedings of the Royal Society B: Biological Sciences 272: 1473-1479.

Manning, J. 2002. Digit ratio. New Brunswick, NJ: Rutgers University Press.

Manning, J., Scutt, D., Wilson, J. \& Lewis-Jones, D. 1998. The ratio of 2 nd to 4 th digit length: a predictor of sperm number and levels of testosterone, LH and oestrogen. Human Reproduction 13: 3000-3004.

Manning, J., Callow, M. \& Bundred, P. 2003. Finger and toes ratios in humans and mice: implications for the etiology of diseases influenced by HOX genes. Medical Hypotheses 60: 340-343.

Mortlock, D. \& Innis, J. 1997. Mutation of HOXA13 in hand-foot genital syndrome. Nature Genetics 15: 179180.

Noghanchi, E. \& Javanbakht, H. 2019. Study of Sexual Dimorphism in Second-to-Fourth Digit Length Ratio (2D: 4D) in the Green-Bellied Lizard (Darevskia cholorogaster) from Iran. Journal of Genetic Resources 5: 45-50.

Peters, M., Mackenzie, K. \& Bryden, P. 2002. Finger length and distal finger extent patterns in human. American Journal of Physical Anthropology 117: 209-217.

Rajabi, F. \& Javanbakht, H. 2019. Sexual Dimorphism in Digit Length Ratios in Marsh Frog, Pelophylax ridibundus (Ranidae) from Iran. Journal of Applied Biological Sciences 13: 33-36.

Utz, D., Gaulin, S., Sporter, R. \& McBurney, D. 2004. Sex hormones and finger length. What does 2D:4D indicate? Evolution and Human Behavior 25: 182199.

Romano, M., Rubolini, D., Martinelli, R., Bonisoli, A. \& Saino, N. 2005. Experimental manipulation of yolk testosterone affects digit length ratios in the ringnecked pheasant (Phasianus colchicus). Hormones and Behavior 48: 342-346.

Romano, M., Leoni, B. \& Saino, N. 2006. Examination marks of male university students positively correlate with finger length ratios (2D:4D). Biological Psychology 71: 175-182.

Roney, J., Whitham, J., Leoni, M, Bellem, A, Wielebnowski, N, \& Maestripieri, D. 2004. Relative digit lengths and testosterone levels in Guinea baboons. Hormones and Behavior 45: 285-290.

Rubolini, D., Pupin, F., Sacchi, A., Gentilli, M., Zuffi, P., Galeotti, H. \& Saino, N. 2006. Sexual dimorphism in digit length ratios in two lizard species. Anatomical Record 288: 491-497.

Trivers, R., Manning, J. \& Jacobson, A. 2006. A longitudinal study of digit ratio (2D:4D) and other finger ratios in Jamaican children. Hormones and Behavior 49: 150-156.

Williams, T., Pepitone, M., Christensen, S., Cooke, B., Huberman, A., Breedlove, N., Breedlove, T., Jordan, C. \& Breedlove, S. 2000. Finger-length ratios and sexual orientation. Nature 404: 455-456.

How to cite this article:

Alinezhadi, I., Heidari, N. \& Javanbakht, H. 2020. Sexual dimorphism in digit length ratios of the second to fourth digits (2D:4D) in two species of green toads (Pelobates syriacus Boettger, 1889 and Bufo viridis (Laurenti, 1768)). Nova Biologica Reperta 7: 295-303. (In Persian).

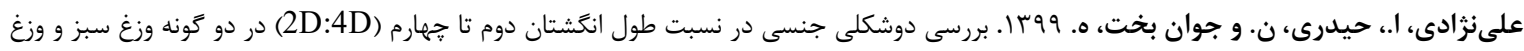

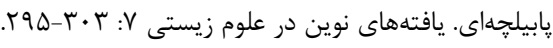

